\title{
Bond Strength of One-Step Adhesives under Different Substrate Moisture Conditions
}

\author{
André Luís Faria-e-Silva \\ Mayra Melo Fabiãob \\ Ravana Angelini Sfalcin ${ }^{b}$ \\ Murilo de Souza Menesesc \\ Paulo César Freitas Santos-Filhoc \\ Paulo Vinícius Soares ${ }^{c}$ \\ Luís Roberto Martins ${ }^{d}$
}

\section{ABSTRACT}

Objectives: The aim of this study was to evaluate the bond strength of one-step adhesive systems to dry or moist dental substrate.

Methods: Thirty human third molars were sectioned into two halves, in the mesio-distal direction, parallel to the long axis of the tooth. Each half was embedded in a polystyrene resin cylinder so that the buccal/lingual surface remained exposed. This exposed surface was abraded to obtain both flat exposed enamel and dentin. The samples were randomly allocated according to the adhesive system (Xeno III, Adper Prompt and iBond) and moisture condition (dry and moist). The substrates were air-dried for $30 \mathrm{~s}$ for dry condition, while the moist substrates were re-wet with $2.5 \mu \mathrm{l}$ of distilled water after drying. After the adhesive procedures, two resin composite cylinders were build-up on dentin and enamel substrates, totaling four per sample. A shear load was applied to the samples at a crosshead speed of $0.5 \mathrm{~mm} / \mathrm{min}$ until failure. Data were statistically analyzed by three-way ANOVA and the Tukey test ( $\alpha=0.05)$.

Results: The evaluated one-step adhesives showed higher bond strength to dentin than enamel. The iBond presented better bond performance to moist substrate and Xeno III to dry substrate. The moisture condition did not interfere in the performance of Adper Prompt. The Xeno III and iBond presented higher bond strength than the other adhesives to both dry and moist substrates.

Conclusions: The moisture condition of substrate interfered in the performance of one-step selfetching adhesives and the best moisture condition was material dependent. (Eur J Dent 2009;3:290296)

Key words: Bond strength; One-step adhesives; Moisture; Self-etching adhesives.

a Professor of Dentistry Department, State University of Montes Claros, Brazil.

b Graduate student of Restorative Dentistry Department, State University of Campinas, Brazil.

Professor of Restorative Dentistry Department, Federal University of Uberlândia, Brazil. d Professor of Restorative Dentistry Department, State University of Campinas, Brazil.

Corresponding author: André Luís Faria-e-Silva Dentistry Department, State University of Montes Claros, Brazil.

E-mail: andrelfsilvalahotmail.com 


\section{INTRODUCTION}

The fundamental principle of bonding to dental hard tissues is based on micromechanical interlocking of the adhesive resin with dentin/enamel surfaces. ${ }^{1,2}$ While bonding to enamel depends on the micromechanical retention to the etched substrate, bonding to dentin relies on hybridization with the exposed collagen mesh. ${ }^{3}$ The current dental adhesive systems rely on different strategies for bonding to the dental substrates. In etch-and-rinse systems, a conditioner lusually $30-40 \%$ phosphoric acid) selectively dissolves the hydroxyapatite crystals and creates spaces for infiltration; ${ }^{3,4}$ the acid gel needs to be removed and the dentin kept moist for adhesion. ${ }^{5,6}$ However, managing the proper moisture condition is a critical procedure. In order to reduce the techniquesensitivity and simplify the bonding procedures, self-etching adhesive were introduced. 4,7,8

The concept of self-etching is based on the use of a non-rinse acidic primer that simultaneously etch and penetrate the dental substrates, ${ }^{9}$ presenting either one or two application steps. In twostep systems, the priming step is followed by application of free-solvent adhesive resin. ${ }^{8}$ Although two-step systems generally present adequate bonding performance, new single-step systems are constantly introduced into the market. These systems are mixtures of acidic resin monomers, additives, solvents and water. 9,10 Water is required to enable dissociation of the acidic monomers responsible for etching. ${ }^{9}$ However, excess water might interfere with the polymerization of the adhesives. ${ }^{11}$ Thus, solvents, such as ethanol and acetone are added to accelerate water elimination. ${ }^{9}$

Most manufacturers recommend that selfetching adhesive should be applied to dry substrate. Therefore, the water contained in the adhesive needs to be sufficient to ionize the acid monomers without, however, compromising the polymerization process. ${ }^{9}$ The first generation single-step self-etching adhesives were presented in two bottles that needed to be mixed before use. This mode of presentation permits water and acidic monomers to be in different bottles, hence the ionization process does not occur before the components of the two bottles were mixed, allowing the addition of a high water content. However, some recently introduced one-step self-etching systems present only one bottle in order to simplify the procedure by eliminating the mixing of solutions. These systems probably present lower water content and therefore might need water from the substrate for proper ionization.

Despite the adequate performance on dentin, one-step self-etching adhesives present limitation in properly bonding to enamel, probably due to the relatively high $\mathrm{pH}$ compared with phosphoric acid. ${ }^{1,4}$ Conventional bonding tests usually do not allow the evaluation of dentin and enamel substrates in the same specimen. Shear bond strength tests with reduced bonding area have been widely used because this reduction allows regional mapping and preparing multiple specimens from the same tooth. ${ }^{12}$ The experimental setup of this methodology allows both substrates to be evaluated in the same specimen. In addition, the orientation of enamel prisms and dentin tubules obtained with this type of preparation are close to the orientation presented in the lateral walls of tooth cavities in clinical situation. ${ }^{13}$

The aim of this study was to evaluate the bond strength of three one-step adhesive systems to dry or moist dentin and enamel. The null hypotheses tested were: (1) the moisture condition of substrate would not affect the bond strengths; and (2) no significant differences in bond strength between enamel and dentin would be detected.

\section{MATERIALS AND METHODS}

Thirty human third molars stored in 0.05\% thymol saline solution for no more than 3 months were used. In order to obtain two halves, the teeth were sectioned to the mesio-distal axis, parallel to the long axis of tooth, using a slow speed diamond saw under water cooling. Each half was embedded in polystyrene resin to facilitate handling, keeping the buccal/lingual surfaces exposed. The surfaces were wet-ground with 320-grit SiC papers (Carburundum, Vinhedo, SP, Brazill until a flat surface on both enamel and dentin was obtained, with sufficient area to build up resin composite cylinders (1 $\mathrm{mm}$ in diameter), as shown in Figure 1. The specimens were rinsed with water and debris were ultrasonically cleansed for $20 \mathrm{~min}$. The dental surfaces were wet-polished with 600-grit SiC papers to standardized the smear layer. Thereafter, the bonding procedures were immediately performed. 
The specimens were randomly allocated according to adhesive procedure. The adhesive systems used in this study, with their batch numbers, manufacturers and compositions are listed in Table 1. Each one-step self-etching adhesive was used with two moisture conditions. The substrate surface was extensively air-dried for $30 \mathrm{~s}$ with oil-free compressed air. The surface was either kept dry (no water rinsing) or left wet after rinsing it for $10 \mathrm{~s}$ with $2.5 \mu \mathrm{l}$ of distilled water using a pipette (Micropipet, Pipetman, Gilson, NY, USA). For application of Adper Prompt, one drop of each bottles $A$ and $B$ were mixed, applied to dental surface and agitated for $15 \mathrm{~s}$. An additional layer was applied, gentle air-dries and light polymerized for $10 \mathrm{~s}$. For iBond samples, three consecutive coats were applied, left undisturbed for $30 \mathrm{~s}$ and then

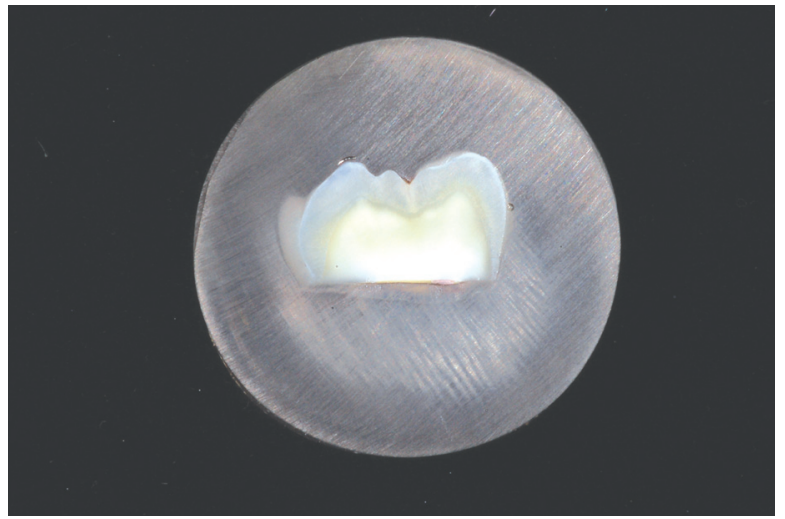

Figure 1. Abraded hemi-section of a human molar, exposing flat dentin and enamel surfaces. gently air-dried. This adhesive was light polymerized for $20 \mathrm{~s}$. For application of Xeno III, equal amounts of bottles $A$ and $B$ were mixed, applied to tooth substrates and left undisturbed for at least $20 \mathrm{~s}$. After brief air-drying, the adhesive was light polymerized for $10 \mathrm{~s}$.

After the adhesive procedures, polyvinyl siloxane (Aquasil, Dentsply DeTrey, Konstanz, Germany) molds with a cylinder-shaped orifice $11 \mathrm{~mm}$ in inner diameter $\times 2 \mathrm{~mm}$ in height) were individually placed onto the dentin and enamel surfaces. The composite resin Filtek Z-350 (3M ESPE, St. Paul, MN, USAl was used to fill the orifices. The resin composite was light polymerized for $20 \mathrm{~s}$. Light polymerization procedures were performed using the quartz-tungsten-halogen curing unit Optilux 501 (Demetron Kerr, Orange, CA, USA) with approximately $650 \mathrm{~mW} / \mathrm{cm}^{2}$ irradiance. Afterwards, the molds were removed to expose the resin cylinders. Two cylinders were made on both dentin and enamel substrates for each tooth ( $n=4$ per specimen), as shown in Figure 2.

The embedded specimens were attached to the testing device and each resin composite cylinder was tested on a mechanical testing machine (EMIC DL 2000, São José dos Pinhais, PR, Brazil). A thin steel wire $(0.2 \mathrm{~mm}$ in diameter) was looped around each cylinder and a shear load was applied to the base of the cylinder at a crosshead speed of $0.5 \mathrm{~mm} / \mathrm{min}$ until failure (Figure 2). Shear bond

Table 1. Adhesives systems: manufacturer, batch number and composition.

\begin{tabular}{|c|c|c|c|}
\hline Adhesive system & Manufacturer & Batch number & Composition \\
\hline \multirow{2}{*}{ Adper Prompt } & \multirow{2}{*}{$\begin{array}{c}\text { 3M ESPE, St Paul, MN, } \\
\text { USA }\end{array}$} & Liquid A: 238002 & $\begin{array}{l}\text { Liquid A: Methacrylic phosphates, Bis-GMA, } \\
\text { photo-initiator }\end{array}$ \\
\hline & & $\begin{array}{l}\text { Liquid B: } \\
242929\end{array}$ & $\begin{array}{l}\text { Liquid B: Water, HEMA, polyalkenoic acid } \\
\text { polymer, stabilizers }\end{array}$ \\
\hline iBond & $\begin{array}{l}\text { Heraeus Kulzer, Hanau, } \\
\text { Germany }\end{array}$ & 10086 & $\begin{array}{l}\text { UDMA, 4-META, glutaraldehyde, acetone, } \\
\text { water, photo-initiators, stabilizers }\end{array}$ \\
\hline \multirow{2}{*}{ Xeno III } & \multirow{2}{*}{$\begin{array}{l}\text { Dentsply De Trey, } \\
\text { Konstanz, Germany }\end{array}$} & $\begin{array}{l}\text { Liquid A: } \\
0702000544\end{array}$ & $\begin{array}{c}\text { Bottle A: HEMA, ethanol, water, aerosil, } \\
\text { stabilizers (BHT) }\end{array}$ \\
\hline & & $\begin{array}{l}\text { Liquid B: } \\
0702000545\end{array}$ & $\begin{array}{l}\text { Bottle B: Pyro-EMA, PEM-F, UDMA, CQ, BHT, } \\
\text { ethyl-4-dimethylaminobenzoate (co-initiator) }\end{array}$ \\
\hline
\end{tabular}

* Information provided by the manufacturers.

Bis-GMA: bisphenol-A glycidyl dimethacrylate; HEMA: hydroxyethyl methacrylate; UDMA: urethane dimethacrylate; $C Q$ : camphorquinone; 4-META: 4-methacryloyloxyethyl trimellitate anhydride; BHT: butylhydroxytoluene; PEM-F: pentamethacryloyloxyethylcyclohexaphosphazene monofluoride; Pyro-EMA: tetramethacryloyloxyethyl pyrophosphate. 
strengths were calculated and expressed in MPa. The average value of the two bonded cylinders for each substrate in the same specimens was recorded as the shear bond strength for that specimen. Data were submitted to three-way ANOVA (dental substrate $\times$ moisture condition $\times$ adhesive system) and the Tukey test at a $95 \%$ confidence level. The fractured specimens were mounted on aluminum stubs, coated with gold (SCD 050, Baltec, Vaduz, Liechtenstein) and evaluated by scanning electron microscopy (JSM-5600LV, JEOL, Tokyo, Japan). The failure modes were classified as follows: Type $1-$ adhesive failure between bonding agent and substrate; Type 2- cohesive failure within the substrate; Type 3 - cohesive failure within the composite resin; Type 4 - cohesive failure within the adhesive; Type 5- mixed failure.

\section{RESULTS}

The statistical analysis showed the factors "substrate" $(P<.01)$ and "adhesive system" $(P<.05)$ were significant, as was the interaction between "adhesive system" and "moisture condition" $(P<.01)$. The results of the Tukey's test for the interaction and substrate are shown in Tables 1 and 2 , respectively. In the moist substrate, iBond presented higher shear bond strength than the other adhesives. The opposite was observed in the dry

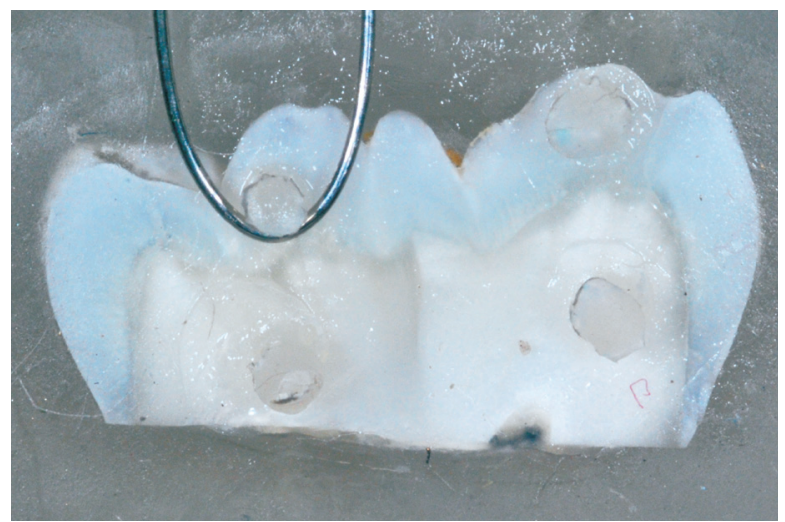

Figure 2. Specimen tested under shear loading.

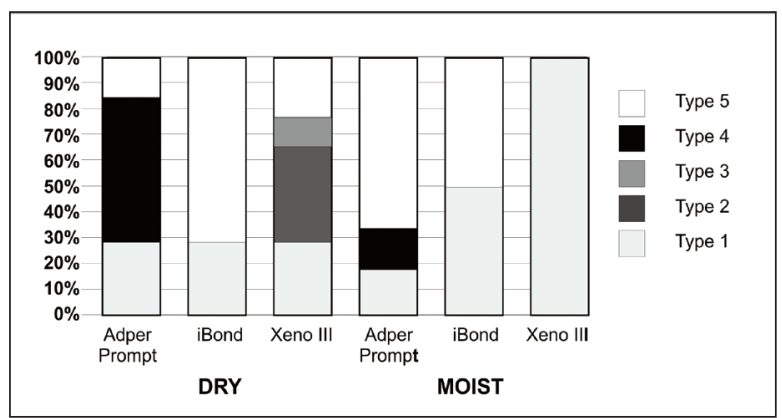

Figure 3. Failure mode of tested specimens in enamel. substrate. There was no difference between the moisture conditions for Adper Prompt. iBond presented higher values in the moist condition, whereas Xeno III showed a better performance on the dry substrate. The evaluated one-step self-etching adhesives showed higher shear bond strength to dentin than to enamel.

The failure modes of the tested samples to enamel and dentin are shown in Figures 3 and 4, respectively. In enamel, there was a predominance of mixed and adhesive failures. Adper Prompt presented some cohesive failures within the adhesive, mainly under the dry substrate condition. For dentin, the cohesive failures within the adhesive were predominant, except for Xeno III applied to moist dentin.

\section{DISCUSSION}

Irrespective of the moisture condition or adhesive system used, the shear bond strength to enamel was lower than to dentin. Enamel has a higher mineral content than dentin, and it requires a solution with lower pH to etch it.4,14,15,16 Despite the relatively low $\mathrm{pH}$ of the one-step self-etching adhesives used in this study, they may have etched the enamel in a less effective manner compared with dentin. This may have resulted in incomplete penetration of the adhesive resin and creation of a more heterogeneous inter-diffusion zone, reducing in bond strengths. Another hypothesis is that the re-precipitation of calcium phosphates may occur into partially desmineralized interfibrillar spaces, impairing the adhesive penetration. ${ }^{17}$ Similar results of better performance of one-step self-etching adhesives bonded to dentin than enamel are reported by Burrow et $\mathrm{al}^{18}$ using micro-shear testing.

Regarding the moisture conditions of substrates, only iBond presented higher bond strength values when applied on the moist substrates. This

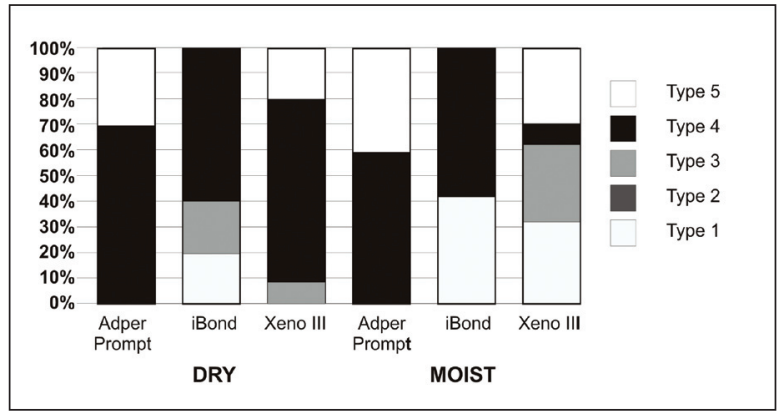

Figure 4. Failure mode of tested specimens in dentin. 
result may indicate that this adhesive needs more water to effectively dissociate the acidic monomers and etch the substrate. iBond is presented in a single bottle, which means that the acidic monomers and the solvents (including water) are together in the same solution. This presentation does not allow a high water fraction to be mixed in the solution. Thus, a moist substrate is necessary for a better performance of this system. Furthermore, acetone is used as a co-solvent to aid in eliminating the excess water. 9,19 The presence of acetone may allow the use of iBond on moist substrates, without compromising its polymerization and performance. However, about $60 \%$ of the failures occurred cohesively within the adhesive on dentin. The higher intrinsic water content of dentin may increase the water fraction and compromise the effective polymerization of the adhesive..$^{20}$

On the other hand, Xeno III presented the highest values on the dry substrate. This adhesive is presented in two bottles, which are mixed before use. This mode of presentation permits water and the acidic monomers to be in different bottles. Thus, the ionization process does occur before the components of the two bottles are mixed, allowing the addition of a high water content. The possibility of having more water allows this adhesive to efficiently etch both enamel and dentin. Despite presenting ethanol as co-solvent to accelerate water elimination, a higher amount of water, can interfere with the adhesive polymerization and reduce the bond strength. ${ }^{20-22}$ In dentin, this effect was more pronounced and there were cohesive failures within the adhesive, mainly under the dry dentin condition. Again, this probably occurred because of the higher intrinsic water content of this substrate. However, these failures did not occur in the moist substrates. The excess of water may also compromise the diffusion of adhesive into the etched substrate. ${ }^{23,24}$ Thus, more mixed and adhesive failures were detected.

Adper Prompt presented similar bond strength under moist and dry conditions. This system, like Xeno III, is presented in two bottles; which allows a high amount of water in it composition. The water content of Adper Prompt seems to be more balanced, and the adhesive presented similar values under both moisture conditions. However, the bond strength values of Adper Prompt were similar to the lowest values obtained with Xeno III (moist) and iBond (dry). Furthermore, it was observed that this adhesive presented more cohesive failures within the adhesive than the others. This can be explained by the absence of a co-solvent, which makes it difficult for the excess water to be eliminated and compromises the performance of this adhesive. ${ }^{9,25}$

The self-etching adhesives were developed in an endeavor to reduce the technical sensitivity of etch-and-rinse adhesive systems. The main limitation of the latter is determining the optimal moisture condition for adhesive application after rinsing dentin to eliminate the phosphoric acid gel. ${ }^{25}$ The present study demonstrated that

Table 2. Shear bond strength means (SD) in MPA.

\begin{tabular}{lcc}
\hline & \multicolumn{2}{c}{ Moisture conditions } \\
Adhesive systems & Moist & Dry \\
\hline Adper Pompt & $10.86(2.46) \mathrm{Ab}$ & $11.63(2.43) \mathrm{Ab}$ \\
iBond & $15.73(5.48) \mathrm{Aa}$ & $10.18(3.62) \mathrm{Bb}$ \\
Xeno III & $10.07(4.37) \mathrm{Bb}$ & $18.73(6.64) \mathrm{Aa}$ \\
\hline
\end{tabular}

Means followed by different letters (upper case - row, lower case - column) differ among them by the Tukey test at the $95 \%$ confidence level.

Table 3. Means followed by different letters (upper case - row, lower case - column) differ among them by the Tukey test at the $95 \%$ confidence level.

\begin{tabular}{lc}
\hline Substrate & Means (DP) \\
\hline Dentin & 15.19 (6.06) A \\
Enamel & 10.54 (3.47) B \\
\hline
\end{tabular}

Means followed by different letters differ among them by Tukey's test at the $95 \%$ confidence level. 
that the moisture condition is also essential for the proper performance of some one-step selfetching adhesives. However, the optimal moisture condition seems to be material dependent and should be investigated in further studies.

\section{CONCLUSIONS}

Based on the results of the present study, it can be concluded that the:

- Xeno III and iBond presented the highest bond strength on dry and moist substrates, respectively.

- The moisture condition did not interfere in the performance of Adper Prompt.

- The one-step adhesives showed higher bond strength to dentin than to enamel.

\section{REFERENCES}

1. Van Meerbeek B, DeMunck J, Yoshida Y, Inoue S, Vargas M, Vijay $P$, Van Landuyt K, Lambrechts $P$, Vanherle $G$. Buonocore memorial lecture. Adhesion to enamel and dentin: current status and future challenges. Oper Dent 2003;28:215-235.

2. Van Meerbeek B, Vargas M, Inoue S, Yoshida Y, Peumans M, Lambrechts P, Vanherle G. Adhesives and cements to promote preservation dentistry. Oper Dent 2001;(Suppl 6):119-144.

3. Nakabayashi N, Kojima K, Masuhara E. The promotion of adhesion by the infiltration of monomers into tooth substrates J Biomed Mater Res 1982;16:265-273.

4. De Munck J, Van Landuyt K, Peumans M, Poitevin A, Lambrechts $P$, Braem M, Van Meerbeek B. A critical review of the durability of adhesion to tooth tissue: methods and results. J Dent Res 2005;84:118-132.

5. Kanca J 3rd. Improving bond strength through acid etching of dentin and bonding to wet dentin surfaces. J Am Dent Assoc 1992; 123:35-43.

6. Reis A, Loguercio AD, Azevedo CL, Carvalho RM, Julio Singer M, Grande RH. Moisture spectrum of demineralized dentin for adhesive systems with different solvent bases. $J$ Adhes Dent 2003;5:183-192.

7. Tay FR, Pashley DH. Have dentin adhesives become too hydrophilic? J Can Dent Assoc 2003;69:726-731.

8. Watanabe I, Nakabayashi N, Pashley DH. Bonding to ground dentin by a phenyl-P self-etching primer. J Dent Res 1994;73:1212-1220.

9. Moszner N, Salz U, Zimmermann J. Chemical aspects of self-etching enamel-dentin adhesives: a systematic review. Dent Mater 2005;21:895-910.
10. Rosa BT, Perdigão J. Bond strengths of nonrinsing adhesives. Quintessence Int 2000;31:353-358.

11. Klein-Júnior CA, Zander-Grande C, Amaral R, Stanislawczuk R, Garcia EJ Baumhardt-Neto R, Meier MM, Loguercio $A D$, Reis A. Evaporating solvents with a warm air-stream: effects on adhesive layer properties and resin-dentin bond strengths. J Dent 2008;36:618-625.

12. Moraes RR, Correr-Sobrinho L, Sinhoreti MA, Puppin-Rontani RM, Ogliari FA, Piva E. Light-activation of resin cement through ceramic: relationship between irradiance intensity and Bond strength to dentin. J Biomed Mater Res B Appl Biomater 2008;85:160-165.

13. Fe Silva AL, Pereira GD, Dias CT, Sartini Paulillo LA. Effect of the composite photoactivation mode on microtensile bond strength and Knoop microhardness. Dent Mater 2006;22:203-210.

14. Pashley DH, Tay FR. Aggressiveness of contemporary selfetching adhesives. Part II: etching effects on unground enamel. Dent Mater 2001;17:430-444.

15. Rotta M, Bresciani P, Moura SK, Grande RH, Hilgert LA, Baratieri LN, Loguercio AD, Reis A. Effects of phosphoric acid pretreatment and substitution of bonding resin on bonding effectiveness of self-etching systems to enamel. $J$ Adhes Dent 2007;9:537-545.

16. Torii Y, Itou K, Nishitani Y, Ishikawa K, Suzuki K. Effect of phosphoric acid etching prior to self-etching primer application on adhesion of resin composite to enamel and dentin. Am J Dent 2002;15:305-308.

17. Hiraishi N, Nishiyama N, Ikemura K, Yau JY, King NM, Tagami J, Pashley DH, Tay FR. Water concentration in selfetching primers affects their aggressiveness and bonding efficacy to dentin. $J$ Dent Res 2005;84:653-658.

18. Burrow MF, Kitasako Y, Thomas CD, Tagami J. Comparison of enamel and dentin microshear bond strengths of a two-step self-etching priming system with five all-in-one systems. Oper Dent 2008;33:456-60.

19. Dickens $\mathrm{SH}$, Cho $\mathrm{BH}$. Interpretation of bond failure through conversion and residual solvent measurements and Weibull analyses of flexural and microtensile bond strengths of bonding agents. Dent Mater 2005;21:354-364.

20. Nunes TG, Garcia FC, Osorio R, Carvalho R, Toledano M. Polymerization efficacy of simplified adhesive systems studied by NMR and MRI techniques. Dent Mater 2006;22:963-972.

21. Baumhardt-Neto $R$, Meier MM, Loguercio AD, Reis $A$. Evaporating solvents with a warm air-stream: effects on adhesive layer properties and resin-dentin bond strengths. $J$ Dent 2008;36:618-625. 
22. Summitt JB, Chan DC, Burgess JO, Dutton FB. Effect of air/water rinse versus water only and of five rinse times of resin-to-etched-enamel shear bond strength. Oper Dent 1992;17:142-151.

23. Hashimoto M, Fujita S, Kaga M, Yawaka Y. Effect of water on bonding of one-bottle self-etching adhesives. Dent Mater $J$ 2008;27:172-178.

24. Tay FR, Gwinnett AJ, Wei SH. Micromorphological spectrum from overdrying to overwetting acid-conditioned dentin in water-free acetone-based, single-bottle primer/ adhesives. Dent Mater 1996;12:236-244.

25. Furuse AY, Peutzfeldt A, Asmussen E. Effect of evaporation of solvents from one-step, self-etching adhesives. $J$ Adhes Dent 2008; 10:35-39. 